\title{
EVALUATION AND MANAGEMENT OF THE DYSPNOEIC PATIENT- A CHALLENGE TO THE ANAESTHESIOLOGIST
}

\author{
Dipanjan Bagchi' ${ }^{1}$, Mohanchandra Mandal'2, Mrinal Saha ${ }^{3}$, Biswanath Sarkar ${ }^{4}$, Sekhar Ranjan Basu ${ }^{5}$
}

${ }^{1}$ Consultant Anaesthesiologist, Department of Anaesthesiology, Howrah District Hospital, Howrah, West Bengal.

${ }^{2}$ Associate Professor, Department of Anaesthesiology, NRS Medical College, Kolkata, West Bengal.

3Postgraduate Trainee, Department of Anaesthesiology, North Bengal Medical College, Darjeeling, West Bengal.

${ }_{4}^{4}$ Postgraduate Trainee, Department of Anaesthesiology, North Bengal Medical College, Darjeeling, West Bengal.

5 Professor and HOD, Department of Anaesthesiology, North Bengal Medical College, Darjeeling, West Bengal.

\begin{abstract}
\section{BACKGROUND}

Anaesthesiologists are not infrequently facing the problematic patient presenting in the pre-anaesthetic clinic with evident dyspnoea, which has not been properly evaluated. Dyspnoea being a presentation of several severe disorders, its evaluation and management remains important even today to modify the risks entailed and to diminish the perioperative complications along with post-operative ventilation. In this perspective, we searched for relevant medical literature in English language using Google Search Engine. A thorough search for articles was done using the following Medical Subject Headings (MeSH) terms such as 'Dyspnoea,' 'Dyspnoea/ aetiology,' 'Dyspnoea/ physiopathology,' 'Dyspnoea/ diagnosis,' 'Dyspnoea/ therapy,' 'Dyspnoea/ psychology,' 'Exercise/ physiology,' 'Respiratory Insufficiency' and 'Sensation.' The full text articles published in last two decades were mainly considered with the exception for some old seminal articles, which dates back to the 50's. Subsequently, the articles are filtered and only the review articles, original investigations, guidelines and editorials were consulted. Framing of this article was envisaged to provide an overview of the varying aetiology of dyspnoea, its work-up and management in the light of recent advances. This may help in the refreshment of knowledge, which can help reducing the perioperative mortality and morbidity of these patients, already living a restricted life-style with a considerable morbidity.
\end{abstract}

\section{KEYWORDS}

Borg Scale, Breathlessness, Dyspnoea, mMRC Scale, Rapid-Shallow Breathing, Respiratory Insufficiency, Sensation.

HOW TO CITE THIS ARTICLE: Bagchi D, Mandal M, Saha M, et al. Evaluation and management of the dyspnoeic patient- a challenge to the anaesthesiologist. J. Evolution Med. Dent. Sci. 2018;7(07):922-928, DOI: 10.14260/jemds/2018/210

\section{BACKGROUND}

Dyspnoea, also commonly known as shortness of breath, is a subjective awareness of discomfort in breathing. The term dyspnoea derives from the Greek word 'dys' meaning 'painful, difficult or disordered' and 'pnoea' meaning 'breathing.' The American Thoracic Society (ATS) defines dyspnoea as 'subjective experience of breathing discomfort' consisting of qualitatively distinct sensations, which vary in intensity.[1,2] The experience results from interactions among varieties of physiological, psychological, social and environmental factors, and may induce secondary physiological and behavioural responses.[1-4] Thus, dyspnoea - often described in terms of air hunger - is a multidimensional and very subjective sensation of work/ effort and of chest tightness and its assessment depends on what the patient says. ${ }^{[1,5-7]}$

\section{Magnitude of the Problem}

Dyspnoea is a debilitating symptom affecting up to $50 \%$ patients admitted with acute illness in tertiary care hospitals and about $25 \%$ of patients in ambulatory care settings. $[2,8]$ Pain is often referred to as the fifth vital sign. Likewise, dyspnoea has been designated by some authorities as the sixth vital sign for individuals suffering from Chronic Obstructive Pulmonary Disease (COPD).[3]

'Financial or Other Competing Interest': None.

Submission 08-01-2018, Peer Review 01-02-2018,

Acceptance 07-02-2018, Published 12-02-2018.

Corresponding Author:

Mohanchandra Mandal,

Flat-2H, Block- A, DKB Green,

57/4, B. T. Road, Kolkata-700002, West Bengal.

E-mail:drmcmandal@gmail.com

DOI: $10.14260 /$ jemds $/ 2018 / 210$

\section{How is Anaesthesia and Dyspnoea Related?}

Anaesthesiologists are concerned with dyspnoea during the preoperative check-up and for the whole perioperative period. Dyspnoea increases the work of breathing, oxygen consumption, heart rate and ultimately leads to intraoperative and postoperative complications including increased probability of postoperative mechanical ventilation, infections, increased hospital stay and even death. Distinguishing the aetiology of dyspnoea is essential for the intervention. Dyspnoea on mild-to-moderate exertion and dyspnoea at rest remains to be prime concern to the anaesthesiologist for possible intraoperative respiratory complications and exacerbated postoperative pulmonary complications. Both these two categories of dyspnoea imply diminishing or already diminished cardiopulmonary reserve, which multiplies the risk of morbidity and mortality in the perioperative period.

\section{Causes of Dyspnoea}

Dyspnoea may result from different causes, which may be broadly differentiated into different categories based on the history and physical examination findings (Table 1).[9,10] These are cardiological, pulmonary, upper airway obstruction and non-respiratory miscellaneous causes (Neuromuscular, haematological, metabolic, endocrine related and renal failure). Among the miscellaneous category, psychological and neurogenic factors like anxiety and panic attacks are common. Among cardiological category, heart failure, ischaemic heart disease, cyanotic heart disease and rheumatic heart disease are the main contributory causes. Atrial myxoma may be another cause. Bronchial asthma, COPD, pneumonia, pneumothorax, pleural effusion, pulmonary fibrosis, etc. are common respiratory causes. $[6,11,12]$ 
Dyspnoea may be induced in Four Basic Clinical Settings-

1. Increased ventilatory demand- which may occur with exertion, fever, metabolic acidosis, severe anaemia or any other hypoxic state.

2. Reduced ventilatory capacity such as pleural effusion, pneumothorax, multiple rib injury or muscle weakness etc.

3. Increased airway resistance such as asthma or COPD.

4. Reduced pulmonary compliance as might occur with interstitial fibrosis or pulmonary oedema.[13]

Dyspnoea is defined as acute when it occurs suddenly or within a few hours in a patient who has not complained shortness of breath previously.[14] Lighezan, et al[15] put forward the 'Rule of $10 \mathrm{P}$ 's as a mnemonic for the common causes of acute dyspnoea. Those are pneumonia, pneumothorax, pulmonary constriction (Asthma), peanut (or other foreign body), pulmonary embolus, pulmonary tamponade, pump failure (Heart failure), peak seekers (High altitudes), psychogenic and poisons.

Chronic dyspnoea is defined as shortness of breath lasting more than one month of duration. ${ }^{[1,16]}$ In other words, chronic dyspnoea is present for some time and worsens slowly over months or even years before the patient seeks medical advice.[14]

\section{Descriptors of Dyspnoea}

Numerous verbal descriptors (The phrases of words used by the patients to express some state or feelings) have been grouped into distinctive clusters to describe dyspnoea. Five descriptive clusters are most frequently selected to express dyspnoea such as chest tightness, increased effort of breathing, unsatisfied inspiratory effort, rapid-shallow breathing and breathlessness. The descriptors $[2,11,17]$ and mechanism[2,6,7,18,19] of dyspnoea have been nicely detailed by several authors and is beyond the scope of present article.

\section{Grading of Dyspnoea}

Measurement of dyspnoea (Breathlessness) is important for purposes of intervention and also for the prognostic reasons. Measurement can be objective or subjective. The assessment of severity of dyspnoea can be deduced from the several standing scales as mentioned below-

1. 'Discriminative' scales (Differentiating study populations based on the level of perceived dyspnoea) or 'evaluative' tools (Identifies variations compared with baseline conditions).

2. 'Categorical' scales (Quantifies the symptoms according to different categories - mild, moderate or severe dyspnoea - as in Borg scale) or 'analogical' (e.g. the visual analogue scale or VAS, which determines the severity of dyspnoea in an analogical fashion).

3. 'Unidimensional' scales (Consider only one type of activity that provokes the dyspnoea) or 'multidimensional' scales (Which take other aspects into account such as functional impairment, the size of task that evokes dyspnoea and the degree of exertion associated to the perceived sensation).[17]

Furthermore, the assessment might be done as 'direct' scales (what investigate directly the level of symptoms perceived) or 'indirect' scales (Evaluate the activities in daily life that is limited owing to dyspnoea). In another way, these may be 'clinical' scales (Information obtained directly from the patients through interview) versus 'psycho-physical' scales (Assess symptom intensity in response to a specific stimulus such as exercise).

\section{Clinical Scales}

These types of scales provide information which is obtained directly from the patients through interview. For example, the modified Medical Research Council (mMRC) is a unidimensional dyspnoea scale related to activities of daily living.[17] This scale is comprised of five statements that describe the entire range of respiratory disability from none (Grade 1) to almost complete incapacity (Grade 5) and well correlated with the quality of life in chronic respiratory diseases such as COPD or idiopathic pulmonary fibrosis. The mMRC scale is user friendly, not time consuming and widely used. The scale does not quantify breathlessness itself, rather it quantifies the disability associated with breathlessness (Table 2).[20,21]

\section{Psycho-Physical Scales}

These types of scales assess symptom intensity in response to a specific stimulus such as exercise. For example, the modified Borg scale or Visual Analogue Scale (VAS) ${ }^{[1,21,22]}$ or a category ratio scale may be used to assess dyspnoea during the initial evaluation and also after treatment on a scale of 10 $\mathrm{cm}$ with markings at every $1 \mathrm{~cm}$. The person is instructed to provide quantification of his/her breathlessness with ' 0 ' as 'no breathlessness' and ' 10 ' as 'intolerable breathlessness' (Table 3).[17,23] It indicates the degree of dyspnoea.

Roizen's grading of dyspnoea can be utilised during preoperative assessment (Table 4).[24] Grades of preoperative dyspnoea are found to be correlated with postoperative survival. Undiagnosed dyspnoea of grade II or worse may require further investigation.

It is also possible to assess the dyspnoea in relation to specific situations such as 'exertional dyspnoea' using tools that can measure the level of dyspnoea in response to a physical stimulus. For example, the New York Heart Association (NYHA) functional assessment can be used to have idea about the severity of heart failure, the severity of dyspnoea and a rough estimate about metabolic equivalent of tasks (METs) (Table 5).[25,26]

\section{Pathophysiology/ Mechanism of Dyspnoea}

Dyspnoea is a non-specific, common symptom of both heart failure and other diseases. This 'shortness of breath' upon exertion is the most common complaint and generally appears early in the development of left heart failure. Similar to dyspnoea, orthopnoea is also not specific for heart failure. Paroxysmal nocturnal dyspnoea is a form of orthopnoea and may occur with further progression of left ventricular failure. In patients of $\mathrm{CHF}$, there are several symptoms that are often not unique to CHF, but collectively those indicate the presence of such disease. Dyspnoea is the first of the symptoms common to CHF. As a patient with CHF lie supine, intrathoracic blood volume increases and left ventricular filling pressure rises. This attributes to the laboured breathing when lying relatively flat in bed and the patient finds relief by assuming a more upright position.[27] 
The pathophysiology of dyspnoea is quite complex. It involves the activation of different pathways that lead to increased work of breathing. Stimulation of the receptors of upper or lower airway, lung parenchyma or chest wall and excessive stimulation of the respiratory centre by central and peripheral chemoreceptors are relayed to the central nervous system via respiratory muscle and vagal afferents. These are consequently interpreted by the individual in the context of the affective state, attention and prior experience, resulting in the awareness of breathing. The clinical evaluation and subsequent management are guided by the clinical presentation and underlying cause. The causes of dyspnoea are manifold and include a spectrum of disorders which extends from benign to serious and life-threatening entities.

Most of the diseases that have symptoms of dyspnoea are associated with an obvious increase in the work of breathing resulting from an abnormality in the respiratory mechanics. This may be due to increase in the elasticity (In restrictive lung diseases) or owing to an obstruction in airflow (In obstructive diseases). A complex interaction between the peripheral receptors (In the pleural membranes, respiratory spindles and lung parenchyma), neural pathways and the central nervous system is responsible for the conscious perception of breathing. The neural pathways are situated in the spinal cord and the vagus nerve. The central pathways involve the carotid body chemoreceptors, the inspiratory neurons in the medulla and the higher cortex. Whenever there is an imbalance between the ventilatory demand and the respiratory output, a subjective feeling of inappropriateness of respiration or dyspnoea results.[28]

The 'length-tension inappropriateness theory' formulated by Campbell and Howell in 1963 mentions a mismatch between the tension generated in the respiratory muscles and the tidal volume as a cause of dyspnoea. This disparity brings the breathing into a conscious level.[7]

In pulmonary congestion, the juxtacapillary J-receptors come into play to initiate dyspnoea. These receptors are supplied by unmyelinated vagal nerve fibres and are situated in the alveolar interstitium. These are stimulated by congestion in the pulmonary bed and initiate the HeringBreuer reflex resulting in shallow and rapid breathing.[7]

In patients with diminished left ventricular ejection fraction or in cardiac dysfunction when the blood is redistributed to the pulmonary circulation in the supine position, the heart cannot pump the excess blood out, resulting in pulmonary congestion and dyspnoea (Orthopnoea) results. Exercise induced dyspnoea may be due to the inability of the left ventricle to increase the oxygen delivery in response to the increased demand of exercising body. During sleep the responsiveness of the central nervous system may decrease and also the adrenergic drive to the myocardium may decrease, which results in a mismatch of the heart rate in proportion to the oxygen demand. This may result in paroxysmal nocturnal dyspnoea.

Many other factors have been proposed to initiate the mechanism of dyspnoea: disturbances in acid-base balance, central nervous system diseases, fatigue of respiratory muscles, increased oxygen demand and abnormal respiratory drive.[13]
Receptors attributed to the Genesis of Dyspnoea[7,18,19]

1. Mechanoreceptors (Vagal afferent).

- Lung: Stretch receptors, J-receptors,

- Respiratory muscles: Muscle spindle (Intercostals), Golgi tendon organ (Diaphragm),

- Airway: Irritant receptors.

2. Chemoreceptors: Carotid bodies, aortic bodies, central medullary chemoreceptors.

3. Central Nervous system: Efferent signals to respiratory muscles.

4. Vascular receptors: Left and right atrial mechanoreceptors, pulmonary artery baroreceptors, right ventricular strain receptors.

\section{Approach to a Patient with Dyspnoea}

The management of dyspnoea primarily involves the management of the underlying pathology. From the history and the clinical symptoms, a primary differentiation should be made between the respiratory and cardiac causes (Table 6).[9]

\section{Approach to Patients with Primarily Respiratory Involvement}

History suggestive of respiratory involvement, history of smoking, history of occupational exposure to dust, asbestos fibres, smoke etc. may be present. There may be a history of expectoration of thick purulent sputum and history of chronic bronchitis, which may point towards a diagnosis of chronic obstructive pulmonary disease (COPD). There may be a history of wheeze and chest tightness on exposure to seasonal weather changes, smoke, dust, household materials and drugs, which is relieved with bronchodilators suggestive of bronchial asthma. A history of onset from the childhood may bear more weight in its favour. Moreover, there may be a history of tuberculosis, pleural effusion, pneumonitis, etc.

Clinical examination may reveal changes predominantly involving the respiratory system as a barrel chest, puffing pattern of breathing, increased resonance (e.g. in COPD), decreased resonance (e.g. in consolidation, effusion, etc.), vocal fremitus, bronchial breath sounds, wheeze, rhonchi and crepitations (mainly coarse in nature). Here, one should opt for a chest roentgenogram (x-ray) and the pulmonary function test (PFT). A CXR may help in primary outlining of the disease, differentiating between effusion, consolidation, pneumothorax, collapse, emphysema and fibrosis. A high resolution computed tomography scan may also be recommended in special situations. Spirometry (PFT) is useful for initial diagnosis and categorisation of COPD or asthma. It helps in differentiating between the COPD and bronchial asthma patients, defined by the FEV1: FEV ratio. However, PFT has not been shown to have any value in reducing postoperative pulmonary complications. Also, the PFT does not play any decisive role in the prognosis of the patient or the outcome. Any interstitial lung disease may be diagnosed with help of the HR-CT scan. It may also help in pin-pointing any growth, etc. in the lung tissue or the mediastinum.

If COPD is the underlying cause, the patient should be optimised with abstinence from smoking, chest physiotherapy and respiratory exercises including incentive spirometry, bronchodilators administered as nebulisation or metered-dose inhalers. Bronchial asthma patients should be 
maintained on steroids by MDIs or by oral administration, administration of Montelukast and avoidance of precipitating factors. Infective lesions can be treated accordingly and ILDs may need special care by pulmonologists.

\section{Approach to Patients with Primarily Heart Disease}

These patients have a definite history of chest pain, hypertension, diabetes of long duration or any heart disease from birth. The dyspnoea has no relation with any of the causes mentioned under the respiratory section. It typically is related with exertion, excitation, hypoxic situation or increased stress such as exercising or climbing heights.

The dyspnoea is associated with increased sweating or swollen feet or cyanosis or chest pain. The patient is found to be huffing and puffing while talking. Obesity may be an associated finding. Peripheral pulses may be hyperdynamic in regurgitant lesions and feeble in stenotic ones. There may be engorged neck veins. The apex may be shifted outwards and towards the left. The apex may be also found to be heaving on palpation and is likely to give a feeling of lifting one's hand when placed over it. There may be associated finding of a parasternal heave or a palpable thrill in the precordial or parasternal area. On auscultation of the precordium, one finds soft first and second heart sounds and there may be an additional third heart sound. There may be some murmur according to the nature of the underlying pathology. The murmur may radiate towards the pulmonary or the aortic region. There may be opening snaps and ejection clicks. Peripheral auscultations over the arteries help us find pistol shot sounds also over the femoral arteries in cases of aortic regurgitation. In the lung fields on auscultation one can come across some fine crepitations, increasing during inspiration and more at the lung bases.

Heart failure patients should undergo investigations regarding their cardiac function. The basic investigation remains the electrocardiogram. In the ECG, one expects to find evidence of recent/ past myocardial infarctions or ongoing ischaemic changes and also complete bundle branch blocks and axis deviations suggestive of underlying cardiomyopathies. There may also be T-wave inversions in lateral chest leads of hypertensive patients suggestive of left ventricular strain. $\mathrm{T}$-wave inversions with tall $\mathrm{R}$ waves in $\mathrm{V} 1$ V3 may suggest a right ventricular strain in long standing COPD patients, which may indicate their predisposition to develop cor pulmonale. There may be a wide, notched or biphasic P-wave suggestive of atrial enlargement; tall, peaked $\mathrm{P}$-waves on the other hand may suggest full-blown COPD. The ECG may also be indicative of any conduction defect, which may be the only manifestation of a cardiomyopathy or an underlying ischaemia.

If the electrocardiogram is abnormal or even with a normal ECG if the patient is symptomatic, the next step in the ladder remains the echocardiogram. The echocardiogram in itself remains very informative and when combined with a colour-Doppler study may provide valuable information for the anaesthesiologists. There may be a malfunctioning heart valve, which may need medical or surgical intervention in the form of valvotomy, valvuloplasty or valve replacement. There may be some hypokinetic or akinetic segment in patients suffering from past ischaemia or/and myocardial infarction. The ventricular function may also be compromised in the long-term hypertensive or in the cardiomyopathic patient.
Patients having ischaemic heart disease should undergo an angiography if needed followed by stenting or coronary bypass to improve the coronary circulation and cardiac function. Severe systolic dysfunction may have to be solved with the help of external cardiac pumps. Intra-aortic balloon pumps may also help in improving the cardiac function. We may also get an estimate of the pulmonary circulation and the pulmonary arterial and venous resistance from an echocardiographic view.

An exercise treadmill test can also be performed for evaluation of dyspnoea along with chest pain. This test is helpful in diagnosing underlying ischaemia, myocardial dysfunction and undetected hypertension. When the TMT is negative, one can be able to rule out any ischaemic cause of dyspnoea and look for any other cause.[29] Cardiopulmonary exercise testing (Laboratory based) may be done to assess the cardiac function, pulmonary gas exchange capability, ventilation and physical fitness. It can be resorted to in very special situations where the extent of the pathology underlying the dyspnoea is not evident even on clinical examination or baseline investigations or where the patient's conditions (Obesity, exercise-induced asthma, etc.) preclude the treadmill testing. This test involves measurement of different parameters such as heart rate, rhythm, oxygen consumption, carbon dioxide production, dyspnoea, chest pain, leg pain, etc. The patient exercises on a bicycle ergometer or a treadmill, and breathes into a mouthpiece. Oxygen consumption is measured using a pulse oximeter or via an arterial line. It helps us to assess the abnormality in the pulmonary, cardiac or skeletal muscle systems.[29,30]

The 6-minute walking distance test (6MWT) is a practical method of evaluating functional exercise capacity by measuring the distance that a patient can walk on a flat, hard surface over 6 minutes. It can evaluate the functional changes, assess the prognosis and detect the response to treatment across a wide range of respiratory diseases including COPD. In contrast to tests that focus on a single component of physical function, the 6MWT evaluates the integrated response of pulmonary, cardiovascular and muscular components. Results of this test have been correlated with health status, dyspnoea at rest, maximum exercise capacity and mortality. Logistic requirement is minimal such as a little more than a 100 -foot hallway and a stopwatch. The test is self-paced and dependent on patient motivation; thereby, it measures submaximal exercise tolerance rather than exercise capacity. [30-32]

Incremental (ISWT) and endurance (ESWT) shuttle walking tests: Similar to the 6MWT, the ISWT is a field-based test which does not require sophisticated equipment. However, unlike the 6MWT, the ISWT is externally paced. The walking speed is incrementally increased each minute until the patient is limited by symptoms. The ISWT was developed to provide a field-based equivalent of the more advanced laboratory-based tests to measure peak exercise capacity. The ESWT (a variation of ISWT), is conducted at a constant pace $(80 \%-85 \%$ of peak effort based on a prior ISWT) and continues until the patient is limited by symptoms. A number of studies have demonstrated that the ESWT is responsive to the effects of bronchodilators on exercise tolerance and may have better discriminative power than the 6MWT.[31,32]

Use of an integrated point-of-care ultrasonography (PoCUS) can curtail the time needed to formulate a diagnosis, 
while maintaining an acceptable safety profile. PoCUS is reported to be quite sensitive for the diagnosis of heart failure, while maintaining a standard emergency department (ED) evaluation tool for the differential diagnosis of COPD/asthma, pleural or pericardial effusions, pneumonia and especially pulmonary embolism.[33] As a sonographic tool, echocardiography helps to identify cardiac causes such as valvular pathologies or impaired left ventricular function. Moreover, large intrathoracic tumours compressing central airways and/or the superior vena cava can be visualised by chest ultrasound. Thus, PoCUS is emerging as a feasible and reliable diagnostic approach to the patient with dyspnoea, allowing a reduction in time to diagnosis.[34] Sonography of the neck and chest ultrasound should be included in the routine imaging modality for patients with dyspnoea presenting to ED. ${ }^{[33]} \mathrm{A}$ brief outline of diagnostic tests may be summarised below (Table 7].[15,35,36]

\section{Management of the Patient in the Perioperative Period}

The dyspnoeic patient has two problems: the primary or underlying disease and the problems from the result of this disease. One has to plan the management with a view to both. The management of the primary disease is beyond the scope of this article and may better be discussed in any other scenario. We shall have a brief introspective of the problems resulting from the pathology. The problems which surface are those of increased work of breathing, hypoxaemia and volume overload. These need our primary attention.

Perioperative therapeutic approaches are implemented with the goal to reduce the risk in patients considered to be at higher risk. To reduce postoperative complications, risk reduction strategies should be followed. These are lung expansion manoeuvres, adequate postoperative pain management (Patient controlled epidural or intravenous analgesia), adequate glycaemic control, early mobilisation, selective nasogastric decompression, adequate nutritional support and early start of oral feeding if possible. Complications were determined to be about 17 times higher in patients with a Cardio-Pulmonary Risk Index (CPRI) higher than 4 as compared to patients with CPRI lower than 4.[37]

Patient related risk factors for increased postoperative pulmonary complications (PPC) are higher age ( $\geq 65$ years), presence of COPD and asthma, history of (h/o) smoking, h/o obstructive sleep apnoea, poor general health status (CPRI>4), pulmonary hypertension (Right ventricular systolic pressure > $35 \mathrm{mmHg}$ ), heart failure, low albumin level $(<3 \mathrm{gm} / \mathrm{dL})$ and presence of upper respiratory tract infection. Pulmonary symptoms that need evaluation are dyspnoea, wheezing, chest pain, cough, haemoptysis and sputum production, h/o smoking and drug use, occupational history and presence of any cardiopulmonary co-morbid conditions. [37-39]

Surgery related risk factors include the following: the rate of PPC is inversely proportional to the distance of surgical incision to the diaphragm. Operative duration more than 3 - 4 hours and open surgery (Compared with laparoscopic) bear more risk.[37]

Among the procedure related risk factors- the types of surgery and the emergency surgery are recognised to be the most important predictors. Arozullah's Respiratory Failure Risk Index, a multifactorial risk index, is used by some clinicians for estimation of postoperative respiratory failure. ${ }^{[38]}$ However, it is not preferred by many owing to its complexity and bearing numerous (about 28) independent risk factors. Another tool such as Canet Risk Index (CRI) is also used by others.[40] The advantages of CRI are easy applicability. Although, it also has several variables, but most of those can be filled up from the already existing clinical information.

Neuraxial blockade (Either spinal or epidural anaesthesia) blocks the stress responses to surgery (Neuroendocrine, cytokine and pain threshold) and thereby may improve recovery and prevent complications. Postoperative epidural analgesia may reduce respiratory muscle dysfunction and pain-related hypoventilation. ${ }^{[41]}$ ABG analysis is recommended in patients undergoing thoracic or cardiovascular surgery in the presence of dyspnoea or a history of smoking.[42] Pulmonary rehabilitation (Chest physiotherapy, aerobic exercise, incentive spirometry) should be started in the preoperative period for at least two reasons: firstly for patient education and training so that he/she can perform these better in the postoperative period, and secondly to take the advantage of beneficial effect of these rehabilitatory exercises, if any.

\begin{tabular}{|c|}
\hline Cardiac \\
\hline $\begin{array}{c}\text { Congestive cardiac failure, Coronary artery disease, Acute } \\
\text { coronary syndromes } \\
\text { Arrhythmias, Valvular heart disease, Pericarditis, etc. } \\
\text { Respiratory }\end{array}$ \\
\hline $\begin{array}{c}\text { Chronic obstructive pulmonary disease, Bronchial asthma, } \\
\text { Restrictive lung disease, Interstitial lung disease, Pneumonia, } \\
\text { Acute respiratory distress syndrome, } \\
\text { Pneumothorax, Pleural effusion, Pulmonary oedema, } \\
\text { Pulmonary embolism } \\
\text { Lung cancer, Metastatic lung disease }\end{array}$ \\
Upper Airway Obstruction \\
\hline Epiglottis, Foreign body aspiration, Croup, Laryngeal spasm, \\
Laryngeal tumours
\end{tabular}

\begin{tabular}{|c|c|}
\hline Grade & Description \\
\hline 0 & (Dyspnoea) None \\
\hline 0.5 & Dyspnoea- extremely mild \\
\hline 1 & Very mild \\
\hline 2 & Mild \\
\hline 3 & Moderate \\
\hline 4 & Intense \\
\hline 5 & Rather intense \\
\hline 6 & - \\
\hline
\end{tabular}




\begin{tabular}{|c|c|}
\hline 7 & Dyspnoea- very intense \\
\hline 8 & - \\
\hline 9 & Almost unbearable \\
\hline 10 & Unbearable \\
\hline \multicolumn{2}{|c|}{ Table 3. Revised Borg Scale (Borg Visual Analogue Scale) } \\
\hline
\end{tabular}

\begin{tabular}{|c|c|}
\hline Grade 0 & $\begin{array}{c}\text { No dyspnoea while walking on a level surface at } \\
\text { normal pace }\end{array}$ \\
\hline Grade I & $\begin{array}{c}\text { "I am able to walk as far as I like provided I take } \\
\text { my time" }\end{array}$ \\
\hline Grade II & $\begin{array}{c}\text { Specific street block limitation ("I have to stop for } \\
\text { a while after walking one or two blocks") }\end{array}$ \\
\hline Grade III & $\begin{array}{c}\text { Dyspnoea on mild exertion, } \\
\text { ("I have to stop and take rest while going from the } \\
\text { kitchen to the bathroom") }\end{array}$ \\
\hline Grade IV & Dyspnoea at rest \\
\hline $\begin{array}{r}\text { Grade of dyspnoea caused by respiratory problems and } \\
\text { assessed in terms of walking on a level surface at a normal } \\
\text { pace. }\end{array}$ \\
\hline \multicolumn{2}{|c|}{ Table 4. Roizen's Grade of Dyspnoea } \\
\hline
\end{tabular}

\begin{tabular}{|c|c|c|}
\hline Grade & Functional Limitations & MET \\
\hline Grade 1 & $\begin{array}{c}\text { No breathlessness, No limitations. } \\
\text { limitation of physical activity. Ordinary } \\
\text { physical activity results in fatigue, } \\
\text { palpitation, dyspnoea or angina pectoris } \\
\text { (mild CHF). }\end{array}$ & 77 \\
\hline Grade 3 & $\begin{array}{c}\text { Breathlessness on mild exertion. Marked } \\
\text { limitation of physical activity. Less than } \\
\text { ordinary physical activity leads to } \\
\text { symptoms (moderate CHF). }\end{array}$ & $2-3$ \\
\hline Grade 4 & $\begin{array}{c}\text { Breathlessness at rest. Unable to carry } \\
\text { out any physical activity without } \\
\text { discomfort } \\
\text { (severe CHF). }\end{array}$ & 1.6 \\
\hline MET, metabolic equivalent of tasks, MET is defined as the \\
resting oxygen consumption amounting to 3.5 mL/kg body \\
weight/min.
\end{tabular}

\begin{tabular}{|c|c|}
\hline Symptom & Differential Diagnosis \\
\hline Wheeze & $\begin{array}{c}\text { COPD/emphysema, asthma, allergic reaction, } \\
\text { CHF (cardiac wheeze) }\end{array}$ \\
\hline $\begin{array}{l}\text { Pleuritic chest } \\
\text { pain }\end{array}$ & $\begin{array}{l}\text { Pneumonia, pulmonary embolism, } \\
\text { pneumothorax, COPD, asthma }\end{array}$ \\
\hline Fever & $\begin{array}{l}\text { Pneumonia, bronchitis, tuberculosis (TB), } \\
\text { malignancy }\end{array}$ \\
\hline Cough & Pneumonia, asthma, COPD/ emphysema \\
\hline Haemoptysis & $\begin{array}{l}\text { Pneumonia, TB, pulmonary embolism, } \\
\text { malignancy }\end{array}$ \\
\hline Oedema & $\begin{array}{l}\text { Acute heart failure, pulmonary embolism } \\
\text { (unilateral) }\end{array}$ \\
\hline $\begin{array}{l}\text { Pulmonary } \\
\text { Oedema }\end{array}$ & $\begin{array}{l}\text { Acute and chronic heart failure, end-stage } \\
\text { renal and liver diseases, ARDS }\end{array}$ \\
\hline Tachypnoea & $\begin{array}{l}\text { Pulmonary embolism, acidosis } \\
\text { (including aspirin toxicity), anxiety }\end{array}$ \\
\hline \multicolumn{2}{|c|}{$\begin{array}{l}\text { Table 6. Differential Diagnosis for Some Common } \\
\text { Presenting Symptoms }\end{array}$} \\
\hline
\end{tabular}

\begin{tabular}{|c|c|}
\hline Pulmonary & $\begin{array}{c}\text { Flow-volume curves, total lung capacity, } \\
\text { carbon monoxide diffusing capacity of the } \\
\text { lungs, oximetry or arterial blood gases } \\
\text { during exercise, broncho-provocation } \\
\text { testing, maximal inspiratory and expiratory } \\
\text { respiratory pressures }\end{array}$ \\
\hline Vascular & $\begin{array}{c}\text { Ventilation-perfusion lung scanning, venous } \\
\text { studies of the legs }\end{array}$ \\
\hline Cardiac & Echocardiography \\
\hline $\begin{array}{c}\text { Additional } \\
\text { procedures } \\
\text { for difficult } \\
\text { cases }\end{array}$ & $\begin{array}{c}\text { Cardio-pulmonary exercise testing, } \\
\text { monitoring of cardiac rhythm, radionuclide } \\
\text { cardiac studies, Right or left heart } \\
\text { catheterisation (or both), pulmonary } \\
\text { angiography, high resolution computed } \\
\text { tomographic scanning of chest, lung biopsy } \\
\text { (transbronchoscopic, thoracoscopic, etc.), } \\
\text { monitoring of oesophageal pH (24-hour } \\
\text { study). }\end{array}$ \\
\hline \multicolumn{2}{|c|}{ Table 7. Specific Testing for Unexplained Dyspnoea } \\
\hline
\end{tabular}

\section{CONCLUSION}

The dyspnoeic patient is always hungry for air. In this process, he works out the muscle of respiration beyond their capacity and as such they are always on a verge of collapse. Anything which may somehow affect this balance, thereby may tilt the workload of breathing towards the downhill slope and the patient may land into a phase of respiratory failure resulting in admission to the critical care unit and mechanical ventilation. The critical care unit exposes the already compromised system to a lot of infective materials, ventilation increases it. Also, it is very difficult to wean the patients off the ventilator owing to ventilator dependence, muscle fatigue and secondary infections. Hence, proper diagnosis of the cause of dyspnoea guiding us towards adequate and effective pre-operative interventions and modifications in lifestyle including active management of underlying diseases seems to be most effective for a good perioperative outcome.

\section{REFERENCES}

[1] Dyspnea. Mechanisms, assessment and management: a consensus statement. American Thoracic Society Am J Respir Crit Care Med 1999;159(1):321-40.

[2] Parshall MB, Schwartzstein RM, Adams L, et al. An official American Thoracic Society statement: update on the mechanisms, assessment and management of dyspnea. Am J Respir Crit Care Med 2012;185(4):43552.

[3] Bailey PH, Boyles CM, Cloutier JD, et al. Best practice in nursing care of dyspnea: The 6th vital sign in individuals with COPD. Journal of Nursing Education and Practice 2013;3(1):108-22. https://doi.org/10.5430/jnep.v3n1p108

[4] Baker K, Barsamian J, Leone D, et al. Routine dyspnea assessment on unit admission. Am J Nurs 2013;113(11):42-9.

[5] Baker KM, DeSanto-Madeya S, Banzett RB. Routine dyspnea assessment and documentation: Nurses' experience yields wide acceptance. BMC Nurs 2017;16:3.

[6] Herigstad M, Hayen A, Wiech K, et al. Dyspnoea and the brain. Respir Med 2011;105(6):809-17.

[7] Nishino T. Dyspnoea: underlying mechanisms and treatment. Br J Anaesth 2011;106(4):463-74. 
[8] Lansing RW, Gracely RH, Banzett RB. The multiple dimensions of dyspnea: review and hypotheses. Respir Physiol Neurobiol 2009;167(1):53-60.

[9] Karnani NG, Reisfield GM, Wilson GR. Evaluation of chronic dyspnea. Am Fam Physician 2005;71(8):152937.

[10] Coccia CB, Palkowski GH, Schweitzer B, et al. Dyspnoea: pathophysiology and a clinical approach. S Afr Med J 2016;106(1):32-6.

[11] Scano G, Stendardi L, Grazzini M. Understanding dyspnoea by its language. Eur Respir J 2005;25(2):380-5.

[12] Celli BR, Cote CG, Marin JM, et al. The body-mass index, airflow obstruction, dyspnea and exercise capacity index in chronic obstructive pulmonary disease. N Engl J Med 2004;350(10):1005-12.

[13] Mukerji V. Dyspnea, orthopnea and paroxysmal nocturnal Dyspnea. Chap-11. In: Walker HK, Hall WD, Hurst JW, eds. Clinical methods: the history, physical and laboratory examination. $3^{\text {rd }}$ edn. Butterworths 1990: p. 78-80.

[14] Rao AB, Gray D. Breathlessness in hospitalised adult patients. Postgrad Med J 2003;79(938):681-5.

[15] Lighezan DF, Lighezan R, Cozma D, et al. Acute dyspnea: from pathophysiology, evaluation to diagnosis. TMJ 2006;56(2-3):235-42.

[16] Wahls SA. Causes and evaluation of chronic dyspnea. Am Fam Physician 2012;86(2):173-80.

[17] Crisafulli E, Clini EM. Measures of dyspnea in pulmonary rehabilitation. Multidiscip Respir Med 2010;5(3):202-10.

[18] Burki NK, Lee LY. Mechanisms of dyspnea. Chest 2010;138(5):1196-201.

[19] Gigliotti F. Mechanisms of dyspnea in healthy subjects. Multidiscip Respir Med 2010;5(3):195-201.

[20] Stenton C. The MRC breathlessness scale. Occupational Medicine (Lond) 2008;58(3):226-7.

[21] Banzett RB, O'Donnell CR. Should we measure dyspnea in everyone? Eur Respir J 2014;43(6):1547-50.

[22] Banzett RB, O'Donnell CR, Guilfoyle TE, et al. Multidimensional dyspnea profile: an instrument for clinical and laboratory research. Eur Respir J 2015;45(6):1681-91.

[23] Kumar RV. Breathlessness \& respiratory diseases. Lung India 2006;23:34-8.

[24] Nunn JF, Milledge JS, Chen D, et al. Respiratory criteria of fitness for surgery and anaesthesia. Anaesthesia 1988;43(7):543-51.

[25] Ponikowski P, Voors AA, Anker SD, et al. 2016 ESC Guidelines for the diagnosis and treatment of acute and chronic heart failure. The Task Force for the diagnosis and treatment of acute and chronic heart failure of the European Society of Cardiology (ESC) developed with the special contribution of the Heart Failure Association (HFA) of the ESC. Eur Heart J 2016;37(27):2129-200.

[26] National Heart Foundation of Australia and the Cardiac Society of Australia and New Zealand (Chronic Heart Failure Guidelines Expert Writing Panel). Guidelines for the prevention, detection and management of chronic heart failure in Australia. Updated October 2011.

http://www.heartonline.org.au, Accessed on October 29, 2017.

[27] Armstrong CS, Hoover JM, Fox CJ, et al. Anesthesia and congestive heart failure: pathology, medical and surgical management. Middle East J Anaesthesiol 2006;18(5):825-50.

[28] Bass JB. Dyspnea. Chap-36. In: Walker HK, Hall WD, Hurst JW, eds. Clinical methods: the history, physical, and laboratory examination. $3^{\text {rd }}$ edn. Butterworths 1990: p. 200-2.

[29] Morgan WC, Hodge HL. Diagnostic evaluation of dyspnea. Am Fam Physician 1998;57(4):711-6.

[30] Bevacqua BK. Pre-operative pulmonary evaluation in the patient with suspected respiratory disease. Indian J Anaesth 2015;59(9):542-9.

[31] O'Donnell CR, Schwartzstein RM, Lansing RW, et al. Dyspnea affective response: comparing COPD patients with healthy volunteers and laboratory model with activities of daily living. BMC Pulm Med 2013;13:27.

[32] O'Donnell DE, Gebke KB. Activity restriction in mild COPD: a challenging clinical problem. Int J Chron Obstruct Pulmon Dis 2014;9(1):577-88.

[33] Kreuter M, Mathis G. Emergency ultrasound of the chest. Respiration 2014;87(2):89-97.

[34] Zanobetti M, Scorpiniti M, Gigli C, et al. Point-of-care ultrasonography for evaluation of acute dyspnea in the ED. Chest 2017;151(6):1295-301.

[35] Berliner D, Schneider N, Welte T, et al. The differential diagnosis of dyspnea. Dtsch Arztebl Int 2016;113(49):834-45.

[36] Zoorob RJ, Campbell JS. Acute dyspnea in the office. Am Fam Physician 2003;68(9):1803-10.

[37] Ozkan M, Kirkil G, Dilektash AG, et al. Summary of consensus report on preoperative evaluation. Turk Thorac J 2015;16:43-52.

[38] Arozullah AM, Daley J, Henderson WG, et al. Multifactorial risk index for predicting postoperative respiratory failure in men after major noncardiac surgery. The National Veterans Administration Surgical Quality Improvement Program. Ann Surg 2000;232(2):242-53.

[39] Diaz-Fuentes G, Hashmi HR, Venkatram S. Perioperative evaluation of patients with pulmonary conditions undergoing non-cardiothoracic surgery. Health Serv Insights 2016;9(Suppl 1):9-23.

[40] Canet J, Gallart L, Gomar C, et al. Prediction of postoperative pulmonary complications in a population-based surgical cohort. Anesthesiology 2010;113(6):1338-50.

[41] Lawrence VA, Cornell JE, Smetana GW, et al. Strategies to reduce postoperative pulmonary complications after noncardiothoracic surgery: systematic review for the American College of Physicians. Ann Intern Med 2006;144(8):596-608.

[42] Milledge JS, Nunn JF. Criteria of fitness for anaesthesia in patients with chronic obstructive lung disease. British Medical Journal 1975;3(5985):670-3. 